\title{
La primera mujer directora de la Orquesta Filarmónica de Montevideo: entrevista con Ligia Amadio
}

\author{
The First Woman Conductor of the Montevideo Philharmonic Orchestra: \\ Interview with Ligia Amadio \\ Marcela Pini Fernández \\ Barbara Maisonnave Arisi', 3 (iD) 0000-0001-7560-9636 \\ Alessandra Paola Caramori ${ }^{4}$ \\ 'Colectivo Unión Trans, Canelones, Uruguay. \\ 15092255 - utrucomunicacion@gmail.com \\ 2Universidade Federal de Santa Catarina, Florianópolis, SC, Brasil. \\ 88.040-900 - ant@contato.ufsc.br \\ ${ }^{3}$ Vrije Universiteit Amsterdam, Amsterdam, Países Bajos. \\ 1081 HV-secretariaat.sca.fsw@vu.nl \\ ${ }^{4}$ Universidade Federal da Bahia, Instituto de Letras, Salvador, BA, Brasil. \\ 40170-115-letras@ufba.br
}

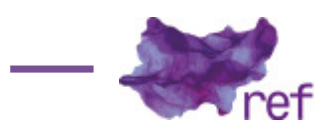

Esta entrevista fue preparada por la uruguaya Marcela Pini, licenciada en Psicología, activista trans, investigadora de la Universidad de la República Uruguay (UDELAR), y por las ítalobrasileñas Barbara Arisi, antropóloga, indigenista y activista LGBTQI2+, profesora licenciada de la Universidad Federal de la Integración Latinoamericana (UNILA), en Brasil, actualmente investigadora Post Doc de la Universidad Federal de Santa Catarina y de la Universidad Libre VU Ámsterdam, en los Países Bajos, y por Alessandra Caramori, lingüista, profesora e investigadora de la Universidad Federal da Bahía (UFBA), en Brasil.

El deseo de entrevistar a la directora de orquesta Ligia Amadio surgió de una feliz coincidencia. Cuando supo por las redes sociales que Ligia Amadio sería la directora de la Orquesta Filarmónica de Montevideo, Barbara escribió a Marcela, preguntándole si no le gustaría entrevistar a Ligia para la Revista Estudos Feministas. Alessandra, ao ser contactada, informó que conocía a Ligia Amaio de niña y que habían estudiado juntas. Las tres compusieron las preguntas en colectivo virtual, Marcela desde Montevideo, donde llevó a cabo la entrevista, Alessandra desde Salvador de Bahía, y Bárbara desde Ámsterdam, Países Bajos. Esa entrevista es fruto de un encuentro y amistades físicas y virtuales, y también de un encuentro físico y afectivo entre Marcela y Ligia en el Teatro Solís, unos días antes de la Marcha de las Mujeres de 8 de marzo de 2017.

Según Marcela, el encuentro con Ligia fue de un disfrute mayúsculo. Lo simbólico jugó un rol preponderante en el encuentro no solo por el lugar en donde se realizó, sino por lo que significa tener por primera vez una mujer en la dirección de la Filarmónica de Montevideo, en un año en que las mujeres en Uruguay no tuvieron tregua en cuanto a feminicidios.

El Solís, ubicado en Montevideo, capital del país, es un ícono de la cultura para todo el Uruguay. Su construcción es del siglo XIX, más precisamente, fue inaugurado el 25 de agosto de 1856. Un encuentro con un Solís en movimiento. Por los pasillos de las oficinas de la Filarmónica transitaban varias personas; Marcela aguardó unos minutos hasta que Ligia la recibiera. 
Desde el comienzo, Ligia les facultó conversar desde un lugar que permitiera conocer a la mujer que ha logrado ocupar un lugar de reconocimiento, en una profesión que mayormente no les brinda generosamente espacio a las mujeres. Se encontraron con una mujer asertiva, cuyas decisiones la posicionaron como una de las mejores directoras de orquesta, sin embargo, sensible, que se conmueve al hablar de sus afectos, que tanto aportaron a su construcción.

Antes, las autoras les presentará brevemente un currículo de la directora. Ligia Amadio nació en São Paulo, Brasil. Estudió en el Colegio Dante Alighieri, y durante 8 años estuvo en la misma clase que Alessandra Caramori, una de las entrevistadoras. Alessandra la recuerda como una niña muy inteligente y reservada. Ingresaron en el mismo año en la Universidad de San Pablo (USP), Ligia en ingeniería y Alessandra en derecho. Ya trabajando como ingeniera, Ligia cursó Dirección de Orquesta (Regência) en la Universidad de Campinas (Unicamp). Hoy, Ligia es una de las más prestigiosas directoras de orquesta del mundo. Alessandra es profesora de Letras y una de las coordinadoras del programa Idiomas Sin Fronteras. Hace poco se reencontraron en las redes sociales, y después personalmente, cuando Alessandra la fue a ver en la dirección de la orquesta Neojibá, en el teatro Castro Alves, en Salvador, sorprendiéndose con su estilo vibrante de dirigir e incentivar a los jóvenes músicos.

Ligia lleva en su currículo actuaciones como directora de orquestas en América Latina, como Brasil, Colombia, Bolivia, Perú, Argentina, Uruguay y México, y en otras partes del mundo, como Japón, Israel, Líbano, Eslovenia y Moldavia. Su discografía es compuesta de 11 CDs y 5 DVDs.

En octubre de 2016, Ligia fue una de las organizadoras del I Simposio Internacional de Mujeres Directoras de Orquestas, con el objetivo de crear un espacio de reflexión y de actuación política para las directoras de orquesta'. Hoy, está al frente de la Orquesta Filarmónica de Montevideo como la primera mujer a ocupar tal espacio. Ella mantiene su blog actualizado, http:/ /ligiaamadio.net, donde reúne su vasto currículo, sus programas de trabajos, así como sus CDs, DVDs y fotografías.

Ojalá disfruten de la entrevista tanto como las autoras la disfrutaron al prepararla y escribirla.

M - ¿Cómo se le hizo la propuesta de que vinieras a ser, nada más y nada menos, la directora de la Filarmónica?

E - Hay un proceso de votación de su director, por la orquesta, un proceso bastante complejo, entonces, durante un año más o menos la orquesta hizo una serie de asambleas, los músicos levantaron nombres que podían ser sus futuros directores, consultaron a estas personas y yo fui una de las candidatas de la orquesta. Después de meses, no sé cómo fue el mecanismo, pero duró meses esto, llevaron a la Intendencia tres nombres, yo y más dos colegas, directores.

M - ¿Varones?

E - Sí, claro, siempre varones, yo soy la excepción, la regla es, al contrario, y la Directora de Cultura, que es Mariana Percovich...

M - Sí, conozco a Mariana.

E - La conoces ino?, pues Mariana, junto con su staff, con su equipo, me eligieron a mí, entre los tres candidatos de esa lista triple que la Orquesta ofreció a la Intendencia para que de ahí eligieran uno de los tres. Yo me quedé muy sorprendida y muy alegre, muy feliz, porque me encanta la orquesta y yo adoro Montevideo. Desde que vine la primera vez, ¿sabe cuándo uno tiene un deseo de vivir en un lugar?, yo dije algún día voy a vivir acá, aunque sea por un periodo de mi vida. Esto siempre me pasa, es gracioso, cuando siento esto por un lugar, yo voy.

M - Interesante ¿no?

E - Si, sí, creo que es un deseo fuerte que después se concretiza, yo creo mucho en esto, yo pienso que primero nace el pensamiento, el pensamiento se hace forma, es como lo que dice la Biblia, el verbo se hizo carne, el primero es la idea, la idea es generadora de la concreción, yo pienso que es así en todo, si nos enfermamos también es así, ¿entiende?, si nos construimos también es así, si mejoramos también es así, con el firme propósito, con el deseo.

\footnotetext{
1 Para conocer más acerca de esa iniciativa feminista encabezada por Ligia Amadio, leer el texto de la directora de Orquesta de Egresados y Estudiantes de la Facultad de Artes de la Universidad de Chile y de la Orquesta Sinfónica Juvenil Regional de Aysén, Ninoska Medel, sobre el II Simposio Internacional de Mujeres Directoras de Orquestra, realizado en Montevideo, Uruguay, entre los días 19 al 21 de octubre de 2018 (MEDEL, 2018).
} 
M - Como para centrarnos también desde América Latina y pensar lo que significa Brasil en América Latina básicamente, quisiera escucharte comentar algo que planteaba Barbara cuando dice que Brasil estaría de espaldas a América Latina, yo creo que por el volumen territorial y por el volumen poblacional que tiene Brasil, es súper autosuficiente, es un continente dentro de otro continente.

E - Exacto, es más bien eso, es como una isla continental ¿no?, está aislada de los otros países.

$M-Y$ justamente con respecto a esto es ¿por qué tu participación en América Latina ha sido tan fuerte?, has transitado por muchas orquestas que tienen que ver con, digo, que son latinoamericanas, con una presencia muy fuerte, siendo obviamente la primera mujer directora en esas orquestas.

E - En muchos lugares, sí, yo fui la primera y la última también, o sea, algunos no volvieron a llamar otras mujeres, o me llaman a mí y no llaman otras, cosas así, yo pienso que fue un poco casual y destino a la vez, nunca sé lo qué es una cosa y lo qué es otra.

M - Uno también busca que le pasen las cosas, ¿no?, sin duda.

E - Casual en el sentido de que yo empecé ganando un concurso en Chile, y la premiación del concurso en Chile era ser directora en Argentina, en Mendoza. Dirigí por primera vez ahí por haber ganado ese concurso de dirección en Chile y de ahí, unos años después, esta misma orquesta de Mendoza me eligió su titular, como acá, y ahí la gente empieza a conocerte acá y allá. En Argentina, todos empezaron a conocer mi trabajo, entonces, uno indicaba para el otro y así va, de un país a otro porque entre los países de América Latina hay mucha circulación, menos Brasil.

M - Un poco eso es a lo que apuntábamos.

E - Por eso. Porque entre por Argentina, me parece, Chile, Argentina, y ahí sí, para hablar la verdad, ahora me acordé de otro detalle, anterior a este. Yo tuve una profesora cubana, Helena Herrera, una gran directora, estudié con ella en Brasil y ella me invitó a Cuba a dirigir su orquesta, varias veces. Cuando ella se tornó la titular en Brasilia, me invitó a ser su asistente, a mí y a otro estudiante suyo. Entonces, empecé a dirigir mi primer concierto con orquesta sinfónica en Cuba, entonces aprendí el español, me costó un poco al principio porque los cubanos tienen un acento muy especial, bastante fuerte, me costaba, pero lo aprendí, los entendía, me comunicaba bien o mal, pero (...)

M - ¿De qué año estamos hablando?

E - Esto fue, creo que 94, 92 o 94, o sea, ya hace bastante, ya hace más de veinte años.

M - ¿En el 91 terminaste el doctorado, el postgrado?

E - No, en el 91 me gradué, simultáneamente, en música porque ya había concluido la ingeniería.

M - Sabemos que eres ingeniera.

E - Si, pero yo estudiaba música y a la vez hacía el postgrado porque como me gradué en ingeniería, me permitían entrar en el postgrado, entonces, entre en el postgrado en artes, no me acuerdo el año, pero más o menos entre en el tercer o cuarto año de la facultad de música, prácticamente lo abandoné, cuando tenía que hacer las calificaciones y todo esto. Porque tenía mucho trabajo y después de diez años me escribe y me dice, mira, tienes la oportunidad de defender la tesis hasta agosto, eso era enero. Entonces yo me puse a trabajar, la defendí el máster y ahora hago el doctorado en San Pablo, el año pasado concluí las asignaturas, y ahora solo tengo la investigación y la tesis para escribir.

M - Quería escucharte sobre esto de implicarte también dentro de lo que es América Latina, también hiciste una convocatoria de directoras el año pasado, ¿verdad?

E - Si, esto fue muy gratificante, muy significativo y muy importante, con toda la modestia de lo que significó armarlo, porque yo lo armé en mi casa con una computadora y con la internet, sin más nada, sin absolutamente nada más, y convencí a mujeres directoras de orquesta de por lo menos diez países a comprar esos pasajes e ir a San Pablo para esa reunión, porque no teníamos nada de plata, nadie nos ayudó, para decir que nadie nos ayudó, la esposa del Intendente de allá, de Fernando Haddad, apoyó nuestra causa, logrando un local para que nos reuniéramos, en Plaza de las Artes, un lugar de la Intendencia, y un coffee break, nos apoyó de esa manera, y estoy muy agradecida, pero digamos que no hubo ningún apoyo de otra especie.

M - ¿Y porque piensas que pasó eso?

E - Bueno, en primer lugar, yo, por estar sola, no tuve el tiempo de ir atrás de sponsors quizás, fui a la municipalidad, pero ellos estaban en su último año de gobierno, no podían hacer una serie de gastos, entonces empecé el trabajo cuerpo a cuerpo, hablando con cada una, buscando a 
cada una, y así fue. No fui atrás, pero todas sabían qué íbamos a realizar, porque lo divulgue muy fuertemente, redes sociales solamente, todos sabían, o sea, tuvo una repercusión te diría mundial, porque en todos los lugares se supo de esto, pero nadie digamos se interesó por preguntar ¿necesitan algo?, ¿apoyamos en algo?, ¿entiendes?, no, no.

M-Y la unión generacional, estuve viendo el programa y las diferentes mesas que se realizaron en el año 2016, hubo un entrecruce generacional y con perspectiva de género.

E - iFue maravilloso! Porque cada mesa tenía una mirada completamente distinta y a la vez universal, me pasó algo muy, muy lindo que fue al final de todo, yo fui al baño y una directora me dice, directora, quiero presentarte a alguien, y era la señora que limpiaba el baño y ella me dijo lo siguiente, ella me dijo que había visto las últimas horas del simposio, no sé, dos, tres horas y dijo que para ella fue tan importante, tan significativo que a ella le gustaría haber asistido a todo, porque le decía mucho a ella (...)

M - Una presencia femenina muy importante.

E - Exacto, era un tema absolutamente universal para todas las mujeres, se entiende, no solo para las directoras, ser directoras era solamente un detalle...

$\mathbf{M}$ - Si, seguramente hay un hilo conductor que transversaliza.

E - Exacto, pero también hay otro que es la condición de género.

M - Sí, claro.

E - Lo que sufrimos como mujeres, todas nosotras.

M - Interesante, Ligia, me gustaría charlar también sobre tu familia, ¿cómo surge esto de "quiero estudiar música", hay una historia familiar que sustenta eso?

E - Sí, sí.

M - ¿Es algo más arriesgado, y más personal?

E - No. Totalmente arriesgado y personal, porque no hay profesionales en esa área en mi familia, en general los músicos ya vienen de familia de músicos, pero digamos que el amor por la música fue algo sembrado desde siempre, porque mi madre es una persona absolutamente musical, ella desde su niñez tiene una voz maravillosa, canta, cantaba, mi madre es de Madeira, de Portugal, de la Isla de Madeira (...)

M - Inmigrante.

E - Si, inmigrante y ella cantaba fados (expresan los malos momentos de la vida a través del canto). De todo esto, nací y crecí, y veo cuando ella canta para mis sobrinos y todos, hasta hoy, que nos, no sé cómo se dice esto...

M - ¿Acunar?

E - Acuna a todos con música de altísima calidad, porque ella es una cantante absolutamente especial, maravillosa.

M - Además de ser tu mamá.

E - No, hablo de esto como profesional, no porque es mi madre, escuchándola, es una voz absolutamente maravillosa, entonces, claro, esto queda en nuestro subconsciente, y además me llevaba en el coro que cantaba en la iglesia, entonces yo iba con ella y veía el órgano de tubos, aquella maravilla que es un órgano maravilloso que había en esta iglesia, y pedí para estudiar el piano con cinco años y ahí, bueno, ahí empecé en la música con cinco años pero no había perspectiva de ser profesional de la música, esto no sé, no nos ocurría, no. Ahí hice la ingeniería, durante la ingeniería me decidí por la música porque vi que mi vocación no era para la ingeniería y yo quería estar en las cosas que amaba, no me importaba si iba a lograr ser alguien o no, si iba a lograr algún éxito, esto no tenía ninguna importancia para mí. Yo quería estar dentro de un teatro, en cualquier función, pero conviviendo con la música, era eso.

M - Interesante, pero tampoco, a ver, la implicancia y el significado que tiene quien dirige una orquesta no es la misma implicancia que tiene, más allá que es sumamente importante, y no estoy con esto restándole importancia, un primer violín...

E - Entiendo, completamente.

M - Pero hay una postura, una cosa que tiene que ver con lo personal, con lo subjetivo con pararse desde otro lugar también.

E - Tus preguntas son muy inteligentes. 
M - Que algo por más que no lo hayas buscado, aunque sea inconscientemente, sin duda, me atrevo a decir que había algo en ti y que hay algo en ti.

E - Sí, de hecho, había, si tú hiciste un camino muy interesante, cómo de no querer ser nada, pasé a ser una directora, o sea, que es el otro extremo de la pirámide, digamos (...). Primero, por dos razones, no sé qué vino antes, la gallina o el huevo. Son dos razones: una, yo ya era suficientemente madura y ¿cómo decirlo?, no ingenua, al punto de saber que yo no tenía más edad para ser una pianista, con veintidós años tú ya quieres serlo, tienes que empezar a querer ser. Aunque yo estudiaba desde los cinco, pero nunca tuve una formación sólida para el piano al punto de tornarme una solista, tampoco para la composición yo me sentía dotada, bendecida, con capacidad. Entonces, pensé en las cosas que podía desarrollar en este momento de mi vida, y que sentía que podía aportar algo con mis capacidades, es la dirección. Por otro lado, yo tenía el carácter y la vocación también, esto es lo que digo el huevo o la gallina, no sé qué vino primero, esto lo descubrí cuando entré en el coro de la Universidad de San Pablo, donde estudié ingeniería, como yo tocaba piano hacía muchos años, luego me pusieron a ensayar las voces, sopranos, contraltos, tenores, bajos y yo era una líder natural, no lo sabía, allí me descubrí, ¿entiendes?, además sabía música mucho más profundamente que todos ellos que estaban ahí. Entonces les enseñaba, tenía ese liderazgo, entonces fueron dos cosas que caminaron juntas, o sea, por un lado, una falta de opción de ser pianista o de ser compositora, podría, si, si yo quisiera sí, pero yo soy muy pragmática, yo dije, no, nunca voy a llegar a una cosa de sofisticada en esta área, porque no tuve la base necesaria, yo ya tenía esta consciencia por mi conocimiento.

M - Una capacidad crítica muy interesante también.

E - Claro, muy grande, claro, y autocrítica.

M-Y además de poder potenciar eso en tu historia, en tu trayectoria profesional, porque muchas veces las personas estamos tan empecinadas en querer hacer aquello que no podemos y le restamos importancia a las cosas que sí, podemos.

E-Se pierde mucho tiempo, exactamente, se pierde mucho tiempo en esto, en lo que no podemos, y hay cosas para la cual estamos preparados. Hay como, no sé si es una preparación de otras vidas o genética o lo que sea, la explicación no me la preguntes, pero sí las personas son vocacionales para una cosa o para otra.

M - Y en el plano familiar, como retomando esa línea, ¿te sentiste apoyada?, ¿cómo fue esto de decir, bueno en realidad mi camino va por acá?

E - Claro, digamos mi familia siempre apoyó mucho los estudios, siempre, mi papá siempre decía lo que tienes en tu cabeza nadie te puede sacar, este es el mayor tesoro que alguien puede tener, me acuerdo de él y me emociono, ¿entiendes? [bajan lágrimas por las mejillas de la directora]

M - No quería hacerte llorar, pero sí, no puedo negar que me gusta que te puedas conectar, en este país de que por más que lo sientas propio, también es un lugar que desde algún lugar también te tenemos que hacer sentir lo mejor posible, y a veces llorar no está tan mal.

E - Gracias.

M - Cuando lloras, seguramente porque lo recuerdas de manera muy positiva...

E - Sí, sí seguro me trae, fue un hombre muy especial.

M - Me van a echar, esta mujer la está haciendo llorar...

E - No para nada, Marcela, eres una luz, no es esto. Claro que causó cierto extrañamiento, hasta él, porque mi padre quería que yo fuera ingeniera y mi mamá no, mi mamá es así, más abierta, entonces en lo que yo dije que quería la música, ella dijo, vete, mi hija, sigue lo tuyo, mi papá también me apoyó, pero diciendo, ¿sabes bien lo que vas a hacer? Abandonar una profesión para lanzarse en algo totalmente (...), para él era una incógnita total, pero sí me apoyaron como me apoyaron en todo en la vida, la verdad.

M - Bueno, pensando en esta, en tu profesión inicial, digamos, no sé si inicial porque sé que durante la mayor parte de tu vida ha estado esto de la música.

E - Sí, antes de todo estuvo la música.

M - Me diste un dato importante, la influencia de tu papá, o sea, en tu formación también. E - Sí.

M - Y pensando en la ingeniería, que creo, al menos como uno lo ve desde afuera, mi formación no ha pasado por ese lugar, pero es algo como muy estructurado, con cierta rigurosidad, creo que eso también es necesario para tu rol, el que has elegido ¿no? 
E -Sí, sí, esto es una observación muy pertinente porque hay en el rigor de la ingeniería, por lo menos en la formación del ingeniero, hay el mismo rigor en la música, y además la ingeniería me ha capacitado para la resistencia, entonces, uno tenía que estudiar mucho y de madrugada, porque durante el día teníamos clase, de las ocho de la mañana a las seis de la tarde y esto me habilitó a tener la resistencia de estudiar mucho, muchas noches sin dormir, y yo seguía haciendo esto en la música, porque lo que haces es trabajar todo el día, y empiezo a estudiar de noche y así va, porque mi trabajo depende de mi estudio, sin estudiar yo no puedo hacer nada, pero además de esto tengo que atender cosas de la oficina, acá los ensayos, que es mi función para organizar la orquesta, entrevista, reuniones, todo el día tenemos cosas que hacer, importantes también, pero no es lo que yo hago, dirigir, o sea, me voy a preparar de noche, de madrugada todo esto. Y otra cosa es el proceso productivo, yo soy ingeniera de producción, acá se llama creo que industrial o algo así, nosotros, cuando construimos un programa para presentar al público, es un proceso productivo, tenemos que transformar una materia disforme en algo completamente rentable y que emocione a la gente, que transmita y que transforme, en el caso de algunas personas, si se penetra muy profundamente en un ser, es algo muy sensible todo esto. Y los tiempos que tenemos, las limitaciones, todo esto es un proceso de producción de algo, de un producto sutil, pero es un producto.

M - De construcción.

E - Totalmente.

M - Cuando decías esto, me hiciste acordar a Paul B. Preciado², es un filósofo que aboga por la Teoría Queer, estudió con Derrida, filósofo francés, la teoría de la deconstrucción. Derrida lo hizo estudiar teoría de la construcción en la universidad de arquitectura, a la facultad de arquitectura, Preciado no entendía por qué, qué tenía que ver la arquitectura con la construcción de la subjetividad. E - Del feminismo, ¿Y?

M - Y bueno, me lo hiciste recordar mucho.

E - Ah, quizás sea esto.

M - Cuánta influencia tienen los modos de construcción y de producción en todos los niveles de nuestras vidas.

E - Estructuración, sí. Sí, totalmente, y en la música, además, ya que hablaste de arquitectura, la música es una construcción arquitectónica total. Yo siempre me remonto a la arquitectura, porque la arquitectura lidia también con lo bello y con la estética, la ingeniería no siempre se preocupa de esto, es más la funcionalidad de todo esto. La arquitectura, además de una base estructural, tiene una base de belleza y todo, por esto yo asocio la música más a la arquitectura que a otras ciencias. $\mathrm{Si}$, y si es como construir. Mi profesora siempre decía, preparar un concierto es como construir una catedral. Yo entiendo lo que es, claro, guardando las infinitas distancias, de la materia de la piedra que llevan siglos y la música, no sé, lleva días, es otra relación, pero es esto es poner pilares, es poner los cimientos, es poner los cimientos, es así. Construir la música es lo mismo.

M - Ya que estamos hablando de música, ahora precisamente, cómo sientes o cómo encuentras, no solamente de tu sentir sino desde tu experiencia como directora en América Latina, ¿̇le tenemos mucho que envidiar a Europa?, ¿poco?, ¿estamos bien? en comparación.

E - ¿En términos de música clásica?

$\mathrm{M}-\mathrm{Si}$, en términos de reconocimiento a nivel orquestal, en términos de profesionalismo, en términos de sabiduría, con este recorrido también que has hecho por América Latina, desde el lugar de profesional, de directora.

E - Yo pienso lo siguiente, dos puntos de vista: uno, lo que nosotros significamos para ellos, dos, lo que ellos significan para nosotros. Nosotros para ellos: no existimos, afuera, valores personales o puntuales, o sea, la América sigue siendo una selva para la Europa, y nosotros habitantes de la selva, y por tanto no tenemos la altura suficiente para llegar, algunos de nosotros, llegan, son respetados pero como individualidades, ellos no piensan que en Brasil, por ejemplo, haya un movimiento musical extraordinario, salvo raras excepciones que conocen, la mayoría no tiene idea, imagina que no puede ir porque va a ser muerto, asaltado, robado y que están todos desnudos en las calles, es así que nos ven.

M - Y que todo Brasil es la Amazonia profunda.

E - Claro y que todas las mujeres brasileñas son prostitutas, es así, es este lugar común y, por otro lado, hay como nosotros miramos a ellos. Todavía existe una mirada de la colonia hacia la matriz,

2 Para conocer más a Preciado, indicamos la lectura de "Carta de un hombre trans al Antiguo Régimen sexual", en su traducción al español (LINDBECK, 2018). 
o sea, todavía existe un mundo de diferenciación y de discriminación, en términos concretos, ahora sin hablar lo subjetivo, como uno ve al otro, en términos concretos nosotros tenemos islas de buen trabajo acá, en la música, lugares como la orquesta sinfónica del estado de San Pablo, que tiene un nivel como las mejores americanas o las mejores europeas. Otras orquestas, la mayor parte de las orquestas latinoamericanas tiene todavía un nivel que tiene que ser perfeccionado, o sea, eso estructuralmente, no nos dan el debido valor, ni la sociedad, ni los que estructuran estas instituciones, sean gobiernos, sean instituciones, fundaciones. La formación del músico ni siempre es la mejor, aunque hay un desarrollo tremendo, principalmente en Brasil, en los últimos treinta años, o sea, cada vez se forman generaciones más fuertes y más perfectas de músicos, se fueron formando escuelas. En otros países hay un movimiento, en Venezuela hay un movimiento maravilloso, ellos están en la cumbre de esto en el sentido de resultados prácticos. Hay movimientos acá en Uruguay y en Argentina, en Colombia, los hay en Chile, en Bolivia hay, ahora mismo fui a dirigir una orquesta que hay en Bolivia para darles como un incentivo, de un director profesional que va a trabajar con ellos. Hay si movimientos de construcción muy lindos, al contrario de la Europa, en el que está habiendo una muerte de las orquestas, al contrario. Yo tengo una amiga que es una mujer brasileña, la primera rectora mujer de una universidad de música alemana [Hochschule für Musik Karlsruhe] , en toda la historia de Alemania, es una brasileña y judía además en Alemania, es una mujer de mucho valor, y Fany [Solter] me dice que si no fueran los extranjeros, no habría más música en Alemania, porque los alemanes no estudian más música, entonces vienen latinoamericanos, vienen orientales, vienen de toda Asia pero de Europa son menos, son poquísimos, entonces, hay cada vez menos interés allá por este arte de alta cultura musical. Entonces, en cuanto ahí hay un recrudecimiento (no sé cómo decir), en otros países hay un florecimiento.

En este momento hay en Brasilla una terrible realidad, no sé si te has enterado, Marcela, están cerrando orquestas, has sabido ino?

M - Sí.

E - Pero me parece que es un momento particular de la política que no tiene nada que ver con lo que se creó. Es que la gente de la política está tan lejos de todo eso.

M - Con la precarización de los contratos de los músicos...

E - Totalmente, ahora es fácil echar a todos, esto fue un plan, un plan que en su momento...ya se veía en el futuro.

M - Y es cultura, Ligia, la cultura hace pensar.

E - Si, claro, no es interesante para quien dirige.

M - No es oportuna en este momento para Brasil.

E - No, no para nada.

M - Para Brasil y a veces, te diré que para otros países de América Latina también.

E - Ah, también, totalmente, está pasando en varias partes.

M-Creo que Uruguay, no sé cuál es tu impresión, estamos desde las limitaciones propias, sabemos qué lugar presupuestal incluso ocupa la cultura en Uruguay, como en América Latina. Pero creo sí que hay como, la directora del Solís, es una mujer muy interesante,

E - Daniela.

M - Daniela Bouret, yo trabajé con ella en alguna oportunidad, cuando ella trabajaba en la Intendencia y, creo, bueno, con Mariana también...

E - No. Uruguay, yo lo veo diferente.

M - ¿Sí?

E - Sí, muy diferente de los otros lugares, acá, primero, hay una verdadera democracia, me parece, la gente dialoga, la gente debate, no existe un verticalismo, yo lo siento así, no sé, y acá por ejemplo es un país chico de población chica, aun así tiene un movimiento cultural extraordinario, comparado a San Pablo, comparado a Buenos Aires, no se quedó atrás para nada, una ciudad que digamos podría ser un barrio de estas grandes ciudades, entre tanto tiene la misma vida cultural o quizás más.

M - Montevideo es una favela de Rio, podría ser.

E - Claro.

M - A nivel poblacional.

E - Exactamente, pero solo a nivel poblacional, no a nivel cultural, ni social. 
M - Y en cuanto a la experiencia latinoamericana ¿qué has encontrado?, ¿mucha diferencia entre un lugar y otro?

E - Sí, porque un amigo me invitó, y yo fui con mucho gusto. Yo allá dirigí la orquesta de Bolivia, es una orquesta digamos con limitaciones, pero con un trabajo de mucho valor, ellos tratan, o sea, nosotros digamos el sur estamos más próximos de la cultura europea, Chile, Brasil, Uruguay, Argentina, los países que van más al norte, tienen muy fuerte su cultura originaria y tienen movimientos increíbles en esta área. México es una excepción porque, aunque tenga una cultura originaria de las más extraordinarias del planeta y fuertes, ellos también tienen un desarrollo en términos de música occidental muy fuerte, tienen orquestas extraordinarias, excelentes. En general nosotros acá, todos nosotros, incluyendo Brasil, tenemos disparidades, grupos buenos y grupos más flojos, grupos absolutamente amateurs, con muchas ganas, con trabajo de valor, pero no nos estructuramos todavía para, quizás el nivel de excelencia que es necesario para una actividad así, como un gran baléo ${ }^{3}$, una gran orquesta, el nivel de excelencia es muy alto realmente que se exige para ser la gran orquesta, el gran baléo. Lo está haciendo Julio Boca acá todo esto, nosotros también estamos trabajando para eso, esperamos cada día más, aproximarnos de un modelo más funcional con más música, y de más calidad siempre para la población que podamos formar nuevas plateas, niños, jóvenes que se interesen por la música. Porque si no, se va a perder todo esto.

M - Como mujer, yo te decía que trabajabas desde las construcciones estético-éticas de los cuerpos, el cuerpo en el sentido más amplio de la palabra, no sólo el cuerpo material. Yo tengo una concepción psicoanalítica, donde creo que el cuerpo se define y se materializa también en función de lo que uno hace y dice que és.

E - Lo que yo hablé en el comienzo de todo acá, si uno se construye, para bien y para mal.

$\mathrm{M}-\mathrm{Si}$, claro.

E - Perdón, te interrumpí.

M - No, siguiendo esta misma línea que tu planteabas. Quisiera escuchar si tú te ves a ti, Ligia, si yo tengo que identificar mi construcción o tengo que poder decirme quien es Ligia, en cuanto a su trayectoria estético-ética.

E - No. Hay una estética también, yo hoy mismo me reunía con nuestro equipo de trabajo, yo les dije, porque, para que entendieran a lo que vengo. Entonces, yo digo, yo no quiero dejar solo una marca por mi música, o sea, que venga a hacer conciertos hermosos, con una línea estética, donde una elección de otros, de compositores, especial. Quiero dejar mi marca, la manera como los músicos se porten en el ensayo delante del público. Quiero dejar mi marca en la manera en que ellos reciben sus materiales de trabajo y se sientan satisfechos con lo que ven y puedan trabajar confortablemente, quiero dejar mi marca en la comunicación de la orquesta, como la orquesta es vista por el público, como ella se promueve. Es esto que llamo de marca, es una construcción estética, es una imagen, es una imagen que no es solo material, es una imagen de ética, es una imagen de ideales, de principios, de valores.

M - De ética, además.

E - Es lo primero.

M-A mí, se me hace difícil separar.

E - Quiero decir, no es solo ético, es todo, todo es ético, el estético también. Claro, claro que sí, porque si una persona quiere aparentar algo, ella está queriendo aparentar un juicio de valor. Está la ética en esto, cuando uno se presenta, quiere mostrar lo que uno piensa que es bueno mostrar o lo que uno quiere lograr obtener.

M - Me gusta mucho la forma de interpretación que tienes y ya te digo, yo trabajo mucho el cuerpo. Algo que me llamó mucho la atención es la extensión de la batuta.

E - ¿Por qué?

M - Porque es menor que la común y tienes una, al menos desde mi visión, corrígeme si no coincides con lo que digo, hay una influencia del cuerpo.

E - Totalmente.

M - Mucho más, en esto de que la batuta es la extensión también del brazo, para mi le quitas importancia a algo muy material, muy simbólico, además, muy masculino, además. Y pones mucha más atención a todo tu cuerpo, pero el cuerpo real.

${ }^{3}$ Amadio utiliza la palabra en español "baléo" para referirse a "ballet". 
E - Totalmente, no tengo nada para corregirte, observaste con mucha profundidad. El uso del cuerpo en este caso para mí es una necesidad de expresión, o sea, yo me aproximo a la orquesta de esta manera, y yo los abrazo de esta manera, yo los traigo hasta mí usando mi cuerpo, quizás otro director no lo necesite, quizás solo con su mente, con su corazón.

M - Lo transmites.

E - Sí, hay otros directores muy sobrios pero que tienen grandes comunicaciones, pero yo necesito esto, es una necesidad personal y quizás un deseo de entregarme, de entregarme a la música y de alguna manera bailarla, pero como directora, no como, bailarina que es muy distinto. El ballet sigue la música, el director genera la música, promueve, viene antes de la música, pero si es un ballet de construcción musical.

M-Interesante. Quiero como puntualizar en el tema de decir, como mujer y, acá si uno siempre habla desde su identidad, es imposible, todo lo que hemos dicho lo has dicho desde el lugar de Ligia. E - Y sí.

M - Si puedes pensarte y mirarte como mujer, ¿cómo te sentís?, o ¿cómo ha sido el proceso este estético-ético de construcción?, ¿con qué te has encontrado?, ¿con qué dificultades?

E - Es muy duro, no es natural, no es aceptado naturalmente. Yo, particularmente, aunque sea muy sensible, tuve una educación muy (como voy a decir) de igualdad de género. Mi padre nunca me trató como si yo fuera la mujercita, al contrario, yo con dos años caminaba con él, en la fábrica, entre las máquinas.

M - ¿A qué se dedicaba tu papa?

E - Mi papa tenía una empresa de mecánica y yo desde nena transitaba, allí eran todos hombres que trabajaban, o sea, yo viví un mundo masculino con mucha naturalidad.

M - Te manejas muy bien, una cosa que hablábamos con Barbara, una de las preguntas que ella sugería, es decir, si vemos tu formación no musical, sino lo que tiene que ver con este legado más paterno, digamos, ahora estoy pensando en este legado paterno. Cuanta influencia tiene tu papá, lo que ha significado también en esta entrevista, ha marcado un poco la ruta también en este momento, y que no es poca cosa para pensar, también Ligia se maneja desde un lugar con cierto grado de comodidad, con cierto grado de plasticidad.

E - No podría estar ahí si no fuera por mi padre, en este sentido como me ha criado, porque mi padre me crió para ser una mujer independiente, absolutamente, o sea, que pudiera transitar en el mundo con total solvencia, y siempre él decía para todos, delante de todos, más vale una mujer que diez hombres en su fábrica. Mi padre era muy, no digo que fuera un feminista, no para nada, o sea, era un hombre como los hombres de su generación, pero digamos, especial. Dar valor a una mujer, él no tenía problema, al contrario, y para el yo tenía que ser una mujer independiente absolutamente, o sea, mi padre y mi madre me construyeron tal como soy. Yo pienso que la discriminación empieza mucho en la casa, desde la niñez, se enseña a los niños a discriminar, a decir esto es para esto, esto es para aquello, todo nace en la formación de la edad más temprana.

M - ¿Sientes que eres una militante?

E - ¿Una militante?, hoy en día sí, siento sí, yo no me sentía antes porque estaba muy ocupada con lo que yo hacía, muy ocupada en estudiar, muy ocupada en formarme. Aunque yo siempre fui militante así un poco de izquierda, esto sí, pero sin estar ligada a un partido ni nada, por mis convicciones, pero como feminista no, nunca fui militante y ahora sí porque entendí el peso de mi ejemplo. Entendí que finalmente después de una edad yo llegué a un lugar que tengo obligación de abrir puertas para otras, yo abrí puertas sola prácticamente, no me las abrí siempre sola, hubo mi primera profesora, esta cubana, también me abrieron puertas, hombres y mujeres, me abrieron puertas. Entonces ahora es mi vez de hacer lo mismo y quizás yo pueda hacer en otro ámbito, como este simposio, como por mis declaraciones, como por una entrevista, como ahora en el concierto del día de la mujer, el día 7, estando en la presencia de las Mujeres de Negro ( Organización de la sociedad que lucha contra la violencia doméstica) que yo estuve, o sea, ahora de una manera mucho más consciente yo estoy tomando la delantera, no digo que yo haya entrado en un movimiento feminista, no, pero con mis conductas, con mi ejemplo, creo que sí puedo decir que hoy soy una militante.

M - Coincido con tu concepto de militancia, la militancia al menos para mí no tiene que ver solamente con ser una activista, que forme parte de un movimiento, me parece que, en la vida, lo que uno muestra de su vida, tiene mucho que ver con la militancia.

E - Si, hoy en día, sí. 
M - La construcción de un nombre, de un nombre de peso y que sea mujer y que sea directora de una orquesta y que tenga una batuta en la mano y que ocupe roles.

E-Y que no sea solo para una misma, que sea un crecimiento que cargue otras personas contigo, esto es muy importante, que traiga junto un montón de gente porque la cantidad de mujeres que ya me dijeron en esta vida después de un concierto, cuánto orgullo tenemos, y no son músicos, son amas de casa. Ahora fui a ver la banda en este barrio Cerro, ¿no?, y varias mujeres vinieron.

Interrupción. [alguien consulta a la directora, pues algunos trabajadores de la orquesta quieren reunirse con ella]

M - Tú sabes la situación que estamos pasando, sin duda, me hablaste recién de Mujeres de Negro, sabes que estamos frente a la inminencia de un paro.

E - Ah sí, maravilloso paro, me parece genial esto, sí.

M - ¿Qué opinión te merece?, ¿cómo hemos llegado a este momento?

E - Por la consciencia, no es que ahora esté peor que antes, es que ahora la consciencia empieza a aflorar, antes era mucho peor, las mujeres, pobrecitas, pero hoy en día, por la consciencia, estamos en un punto que ya no toleramos más, tanta violencia, tanto maltrato, tanta diferencia, ¿entiende?, antes las mujeres, nosotras, nos callábamos, ahora parece que nadie más aguanta, no se soporta más, o sea, yo no creo que ahora se sufra más, las mujeres, no al contrario, las mujeres hoy tienen mucho más espacio, tanto tienen más espacio que ya empiezan a expresarse más ahora.

M - Y sí. El ocupar lugares también significa que haya otros que tengan que desplazarse, dejar el lugar anterior.

E - Sí, ese es el problema, nadie quiere dejar ese lugar.

M - Nadie quiere dejar espacio.

E-Si, exacto.

M - Ligia, ¿qué has dejado por ser Ligia Amado?

E - Muchas cosas, es una construcción que implica pérdidas claro, es mucho sacrificio, mucho trabajo, mucho sacrificio,

M - ¿Con quién vives acá en Montevideo?

E - Nadie. Tengo mi esposo que está en Brasil y mi perro, pero están allá.

M - ¿Hijxs?

E - No, no tuve.

M - ¿Es algo que hubieses querido?

E - En algunas situaciones sí, nunca trabajé para esto, en el sentido de planear, vamos a tener, no, la vida fue pasando y yo siempre me dediqué al otro.

M - Has tenido una vida maravillosa y la seguirás teniendo.

E - Sí.

M - Como para ir cerrando...

E - Perdón que estoy tan sensible, creo que eres tú, eres muy dulce.

M - Bueno, espero que no sea un motivo de angustia.

E - No, al contrario, es muy bueno.

M - Bueno, me alegra que así sea, ¿Qué extrañas cuando estás fuera de tu casa? Y esto a modo de secreto, me comprometo a no difundirlo porque así también podemos hacerte sentir como en casa.

E - Lo que extraño en sí es mi casa, mis flores, mi jardín, mi perro, mi marido por supuesto, mi familia, muchas cosas.

M - ¿Cuánto hace que estás casada?

E - Ahh, veinticinco años.

M - Muchos años.

E - Sí, casada no, vivimos juntos. 
M - Conoces a una pianista que estuvo ahí el año pasado, y esto acá me va a implicar desde algún lugar, Sara Davis, es una pianista, solista, es una mujer transexual y estuvo dirigida por la orquesta que tú diriges.

E - ¿Acá? No, no la vi.

M - Sé por la Filarmónica.

E - Este año tenemos un cantante, una cantante, no sé cómo se denomina ahora, que vamos a tenerla en abril, Lea Amaro, contratenor.

[Interrupción]

M - Sí. Ligia, ¿qué quieres decirnos a los uruguayos en este tiempo que has estado, es decir, que nos falta, que nos agradeces, que no nos agradeces?

E - Ah, yo estoy feliz acá.

M - Yo te sigo mucho en Facebook, me parece tan divertido las cosas que pones, cuando dices: por favor, señoras y señores. Me parece tan divertido.

E - Lea Amaro es un contratenor, o sea, estamos siempre, no teniendo esto como primer valor claro, el primer valor es la música (...)

M - De poder visibilizar a una trans contratenor.

E - Abrir, exactamente. Si es un buen músico, abrir la oportunidad (...)

M - Sí, sin duda, y no has sido directora de orquestas solamente por tu condición de mujer, creo que eso es lo que más ha dificultado que estés ahí.

E - Esto es lo que más ha dificultado, lo mismo en el caso de los transexuales, es lo mismo, este es un gran cantante joven que está surgiendo, pero seguro va a enfrentar muchas dificultades.

M - Sí, claro, sin duda que sí. ¿Qué nos quieres decir a Ixs uruguayxs?

E - Bueno, yo acá me siento tan en casa, tan feliz de estar acá, como te diré, yo soñaba estar acá, yo también construí esto en mi vida. Yo deseaba vivir en la Ciudad Vieja y vine a vivir en la Ciudad Vieja, yo deseaba caminar por esta rambla y así lo hago casi todos los días, en la mañana o en el fin de la tarde. Yo quiero a estos músicos afectivamente, yo los quiero, yo creo en ellos, creo que esta puede ser la gran orquesta, que puede ser. Creo que tenemos que hacer un trabajo en diversos frentes desde la estructuración hasta un trabajo artístico minucioso, pero creo en ellos, quiero estar con ellos. El público es muy, además de cálido, es conocedor, si les gusta, les gusta demostrarlo, si no les gusta, son corteses solamente, entonces uno siente bien la diferencia y es un país súper civilizado, a mí me parece. La gente me va contando cosas, que no es bien así, pero si comparado a Brasil o a otros lugares, acá es mucho más democrático, mucho más civilizado, entonces yo admiro mucho el Uruguay, me siento privilegiada de estar unos años acá, si Dios quiere.

M - Bueno, me alegro, yo quiero decirte que estoy sumamente gratificada de haber podido entrevistarte, de haber logrado esta charla, porque me parece que ha sido un ida y vuelta, me ha sorprendido muchísimo, tú me has sorprendido muchísimo.

E - Tú también, porque tú me sacas algo de adentro muy fuerte.

M-Gracias, pero también cuando uno construye este imaginario, es decir, bueno, es una directora de orquesta, no es la primera orquesta que dirige, es una mujer con mucha trayectoria, que estudió en Europa, que estudió en América Latina, que sigue estudiando, que está haciendo un doctorado, también debe haber una cosa de lo rígido, de lo estructurado y te veo una persona sumamente descontracturada, como maravillosamente puedes conectar esto de deconstruir este imaginario. E - No, yo no soy esa cosa cuadrada de los directores, me daría vergüenza.

M - Bueno, te quiero felicitar, te agradezco mucho, lo disfruté mucho.

E - Yo también.

\section{Referencias}

AMADIO, Ligia. http://ligiaamadio.net.

LINDBECK, Julia. Traducción al castellano de la Carta de un hombre trans al Antiguo Régimen sexual de Paul B. Preciado, filósofo, publicada el 16 de enero de 2018 en Libération. Disponible en 
https://medium.com/@julialindbeck/traducci\%C3\%B3n-de-la-carta-de-un-hombre-trans-alantiguo-r\%C3\%A9gimen-sexual-de-paul-b-95099c295e1 1

MEDEL, Ninoska. Las niñas desertan porque ven que no hay posibilidades o porque hacen diferencias con sus compañeros, Universidad de Chile, 9 Nov 2018. Disponible en https:// www.uchile.cl/noticias/148883/ninoska-medel-participo-en-encuentro-de-directoras-de-orquestas

Marcela Pini (marcepi2007@gmail.com) Mujer Trans. Ex "Trabajadora Sexual”. Activista por los derechos humanos y del Colectivo Trans/Trava/Travesti y Transexual. Licenciada en Psicología (UdelaR), docente e investigadora. Presidenta del Claustro de la Facultad de Psicología (UdelaR).

Barbara Maisonnave Arisi (barbara.arisi@gmail.com) es profesora licenciada de Antropología en la Universidad Federal de la Integración Latino Americana (UNILA), Postdoctoranda de la Universidade Federal de Santa Catarina y de la Vrije Universiteit Amsterdam (proyecto de cooperación CAPES-NUFFIC). Fue directora del Instituto Latino-Americano de Artes, Cultura e Historia (ILAACH, UNILA) (2013/16). Es coautora, con Fernandes, del libro 'Gay Indians in Brazil: untold stories of the colonization of indigenous sexualities' (Springer, 2017).

Alessandra Paola Caramori (alecaramori@gmail.com) es graduada en Derecho y en Letras (portugués e italiano) por la Universidade de São Paulo (USP). Máster en Letras y doctora en Lingüística por la misma universidad. Desde 2009, es profesora de Lengua y Literatura italianas en la Universidade Federal da Bahia. Vicepresidente de lengua italiana del Programa Idioma sin Fronteras.

\section{COMO CITAR ESSE ARTIGO DE ACORDO COM AS NORMAS DA REVISTA}

PINI, Marcela; ARISI, Barbara Maisonnave; CARAMORI, Alessandra Paola. "La primera mujer directora de la Orquesta Filarmónica de Montevideo: entrevista con Ligia Amadio". Revista Estudios Feministas, Florianópolis, v. 28, n. 2, e60326, 2020.

\section{CONTRIBUIÇÃO DE AUTORIA}

Marcela Pini - Realizó la entrevista con la directora del Teatro Solís, preparó las preguntas, las transcribió y las editó.

Barbara Arisi - Idealizó la entrevista, reunió las investigadoras, preparó preguntas, las redactó y las editó.

Alessandra Caramori - Hizo el contacto inicial con la directora, preparó preguntas y revisó el manuscrito.

\section{FINANCIAMENTO}

El presente trabajo fue realizado con apoyo de la Coordenação de Aperfeiçoamento de Pessoal de Nível Superior - Brasil (CAPES) - Código de Financiamento 001

\section{CONSENTIMENTO DE USO DE IMAGEM}

No se aplica.

APROVAÇÃO DE COMITÊ DE ÉTICA EM PESQUISA

No se aplica.

\section{CONFLITO DE INTERESSES}

No se aplica.

\section{LICENÇA DE USO}

Este artigo está licenciado sob a Licença Creative Commons CC-BY International. Com essa licença você pode compartilhar, adaptar, criar para qualquer fim, desde que atribua a autoria da obra.

HISTÓRICO 